\title{
Metronidazole reduces intestinal inflammation and blood loss in non-steroidal anti-inflammatory drug induced enteropathy
}

\author{
I Bjarnason, J Hayllar, P Smethurst, A Price, M J Gumpel
}

\begin{abstract}
This study assessed the effect of metronidazole on the gastroduodenal mucosa, intestinal permeability, blood loss, and inflammation in patients on non-steroidal anti-inflammatory drugs (NSAIDs). Thirteen patients were studied before and after 2-12 weeks' treatment with metronidazole $800 \mathrm{mg} /$ day, while maintaining an unchanged NSAID intake. Intestinal inflammation, as assessed by the faecal excretion of indium-111 labelled neutrophils, and blood loss, assessed with chromium51 labelled red cells, were significantly reduced after treatment (mean (SD) ${ }^{111}$ In excretion 4.7 (4.7)\% v $1.5(1.3) \%(\mathbf{N}<1.0 \%), \mathbf{p}<0.001,{ }^{51} \mathrm{Cr}$ red cells loss $2.6(1.6) \mathrm{ml} /$ day $v 0.9(0.5) \mathrm{ml} /$ day $(\mathbf{N}<\mathbf{1 . 0} \mathrm{ml} / \mathrm{day}), \mathbf{p}<\mathbf{0 . 0 1})$. Intestinal permeability assessed as the 5 hour urinary excretion ratio of ${ }^{51} \mathrm{CrEDTA} / \mathrm{L}$-rhamnose did not change significantly $(0.133(0.046) v 0.154$ $(0.064), p>0.1)$ and there were no significant changes in the endoscopic or microscopic appearances of the gastroduodenal mucosa. These results suggest that the neutrophil is the main damaging effector cell in NSAID induced enteropathy. The main neutrophil chemoattractant in this enteropathy may be a metronidazole sensitive microbe.

(Gut 1992; 33: 1204-1208)
\end{abstract}

Non-steroidal anti-inflammatory drugs (NSAIDs) are among the most successful group of drugs ever developed, with annual prescription rates in excess of 300000 per million subjects in the western world. ${ }^{12}$ While this attests to their efficacy in reducing inflammation and pain, the treatment is not without side effects. The gastroduodenal mucosa is undoubtedly the main site of life threatening complications of NSAID treatment, manifesting as massive haemorrhage or perforation, ${ }^{3-6}$ and indeed NSAIDs may be an important cause of seemingly unexplained sudden deaths in the elderly.

In the past few years it has become clear that the small intestine is also damaged by NSAIDs. In fact long term treatment causes small intestinal inflammation in $70 \%$ of patients. ${ }^{8-10}$ The clinical importance of NSAID enteropathy lies in the associated complications of blood loss, protein loss, and occasional strictures that may require surgery. ${ }^{11-1+}$ Although these complications are not usually life threatening, the consequent iron deficiency anaemia and hypoalbuminaemia (affecting $50 \%$ and $5-10 \%$ respectively of patients with rheumatoid arthritis) are major contributory factors to the morbidity of these patients. ${ }^{1516}$
The pathogenesis of NSAID enteropathy is unknown. It is suggested ${ }^{121718}$ that NSAIDs cause immediate cellular damage during drug absorption perhaps by uncoupling oxidative phosphorylation. This may result in loss of the integrity of the intercellular junctions which is evident as increased intestinal permeability to paracellular probe markers within 12 hours of NSAID ingestion in man. ${ }^{19-21}$ After six months of NSAID treatment inflammation is evident. ${ }^{9}$ It is suggested that the permeability changes allow mucosal exposure of luminal toxins (bile acids, pancreatic juices etc) and this paves the way for a bacterial invasion of the mucosa and hence the neutrophil chemotaxis. ${ }^{121718}$ The participation of bacteria is further inferred from studies showing that pretreating animals with broad spectrum antibiotics before NSAID administration reduces the damage in the small intestine, and some studies show minimal damage in germ free animals. ${ }^{22-26}$ During phagocytosis the neutrophils may cause tissue damage by oxygen free radical generation and lysosomal enzyme release and hence produce bleeding and protein loss. '?

The purpose of this study was to examine the effect of metronidazole on NSAID enteropathy in man. Intestinal permeability, inflammation, blood loss, and gastroduodenal morphology were assessed before and after metronidazole treatment in patients with established NSAID enteropathy.

\section{Subjects and methods}

Twenty patients who had been taking NSAIDs for more than six months underwent a screening phase and all 13 with NSAID enteropathy were recruited to the study. The clinical details of these patients are shown in Table I. Each subject was admitted to a metabolic research ward during these studies. On admission blood was taken for haematology and biochemistry and for leukocyte and red cell labelling. Intestinal permeability was assessed on day 6 and endoscopy was done on day 7. Patients were placed on metronidazole ( $200 \mathrm{mg}$, four times daily) while maintaining an unchanged intake of NSAIDs and were then restudied after 2-12 weeks. Metronidazole was chosen because of its wide use in gastroenterology (diverticulitis, small bowel bacterial overgrowth syndromes, sepsis, etc) and because it has a well defined antimicrobial spectrum.

Sixteen patients with the irritable bowel syndrome acted as controls for the ${ }^{111}$ In leukocyte and ${ }^{51} \mathrm{Cr}$ red cell studies. Twenty healthy white volunteers acted as controls for the intestinal permeability studies. 
TABLE I Clinical details

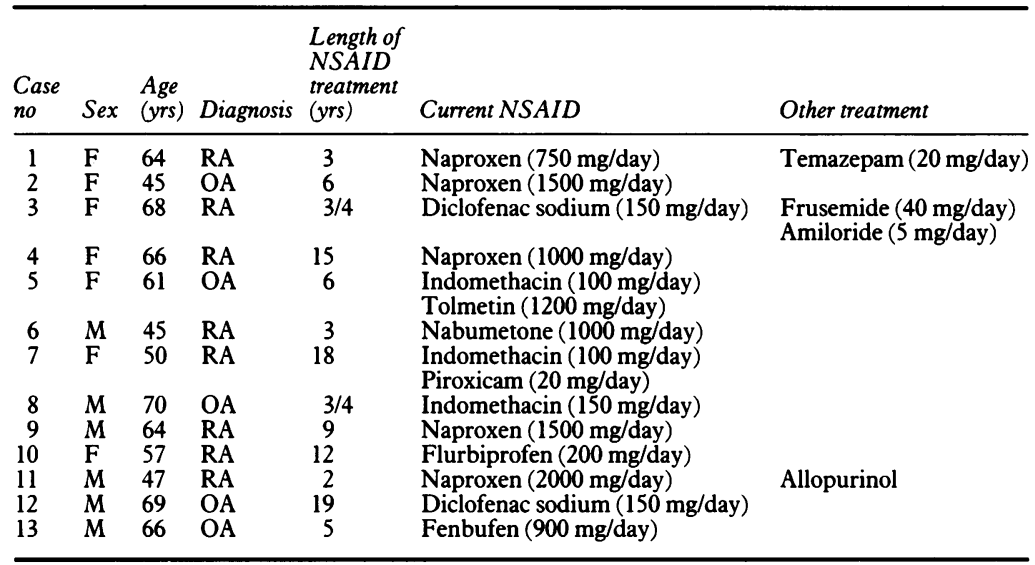

$\mathrm{RA}=$ rheumatoid arthritis; $\mathrm{OA}=$ osteoarthritis.

These studies were approved by Harrow Health Authority Ethical Committee and all patients gave informed consent.

\section{LEUKOCYTE LABELLING 9}

At 10 am on the day of admission an indwelling cannula was placed into an antecubital vein. Sixty $\mathrm{ml}$ of blood were drawn into a syringe containing $11 \mathrm{ml}$ of acid citrate dextrose (National Institutes of Health, formula A), dispensed into two sterile polythene tubes, and allowed to sediment for 1 hour at room temperature. The supernatant was removed and centrifuged at $100 \mathrm{~g}$ for 5 minutes. The supernatant was removed immediately and respun at $300 \mathrm{~g}$ for 10 minutes to yield cell free plasma. The pellet from the $100 \mathrm{~g}$ centrifugation was resuspended and incubated for 10 minutes at room temperature in $0 \cdot 1 \mathrm{ml} \mathrm{HEPES}$ saline buffer ( $\mathrm{pH} \mathrm{7 \cdot 4}$ ) containing $20 \mathrm{mM}$ HEPES in $0.8 \%$ ( $\mathrm{vol} / \mathrm{vol}$ ) sodium chloride, $4.4 \mathrm{mM}$ tropolone, and 400 $\mu \mathrm{Ci}$ (15 MBq) ${ }^{111} \mathrm{InCl}_{3}$ (Amersham International, Amersham, Buckinghamshire, UK). Five $\mathrm{ml}$ of cell free plasma were then added to the cell suspension and centrifuged at $100 \mathrm{~g}$ for 5 minutes. The supernatant containing unlabelled

${ }^{111}$ In was poured off and the labelled cells were resuspended in $6.0 \mathrm{ml}$ of cell free plasma. Five $\mathrm{ml}(9-12 \mathrm{MBq})$ were injected and the rest was used for standards. The labelling efficiency averaged $86 \%$ (range $79 \%-95 \%$ ). The leukocytes maintain their integrity and function during the isolation and labelling procedure. Assuming a $300 \mu \mathrm{Ci}(11 \mathrm{MBq})$ dose of ${ }^{111}$ In is injected, the estimated radiation dose received by the patient during this procedure is 8.5 milliSieverts $(\mathrm{mSv})$ (effective dose equivalent).

\section{${ }^{111}$ In LEUKOCYTE IMAGING AND FAECAL EXCRETION}

Abdominal scintigrams were obtained 1-4 hours (early) and 20 hours (late) after injection of the labelled cells, using an IGE 400 AT $\gamma$ camera with a Star computer at the appropriate channel settings.

Individual faecal excretions were collected over a 4 day period after injection of the labelled cells, with particular care being taken not to contaminate the faecal samples with urine.
Samples were counted in a high resolution bulk sample counter as previously described. ${ }^{9}$ Standards ( $2 \%$ of the injected dose) were made up to $200 \mathrm{ml}$ with water and distributed over a fixed amount of filter paper in a plastic container. Each sample was counted for 20 seconds, which enabled the measurement of $0.01 \%$ of the injected dose with a counting statistical accuracy of $\pm 4 \%$.

\section{RED BLOOD CELL LABELLING ${ }^{11}$}

When blood was obtained for labelling leukocytes, $10 \mathrm{ml}$ were also placed in $20 \mathrm{ml}$ sterile citrate/phosphate/dextrose solution. This suspension was centrifuged at $1500 \mathrm{~g}$ for 10 minutes. Sodium chromate $\left({ }^{51} \mathrm{Cr}\right.$ ) (Amersham International) was added dropwise to the pellet, with continuous mixing, to a final activity of $55 \cdot 5$ $\mathrm{kBq} / \mathrm{kg}$ body weight. This mixture was allowed to stand at room temperature for 15 minutes.

The labelled cells were washed twice in isotonic saline which leaves less than $1 \%$ of the ${ }^{51} \mathrm{Cr}$ unbound. Ten $\mathrm{ml}$ labelled cells were injected into the patient. Daily blood samples were collected and $4 \mathrm{ml}$ of every sample were used as counting standards. Faeces was collected for 5 days and the faecal ${ }^{51} \mathrm{Cr}$ activity was correlated with that of the blood standards from the previous day (which enables the calculation of blood loss into the intestine). The results are expressed as mean daily blood loss. The upper limit of normal for gastrointestinal blood loss is less than $1.0 \mathrm{ml} /$ day. The estimated radiation dose from $55.5 \mathrm{kBq} / \mathrm{kg}$ body weight ${ }^{51} \mathrm{Cr}$ - red cells is $1.2 \mathrm{mSv}$.

Because of the high initial ${ }^{111}$ In activity in the stools, it is necessary to delay counting of ${ }^{51} \mathrm{Cr}$ activity for 3 to 4 weeks to allow the ${ }^{111}$ In to decay.

\section{INTESTINAL PERMEABILITY}

The test solution consisted of $200 \mu \mathrm{Ci}(7 \cdot 4 \mathrm{MBq})$ chromium - 51 - ethylene - diaminetetra - acetate $\left({ }^{51}\right.$ CrEDTA) (Amersham International, Amersham, Buckinghamshire, UK) and $0.5 \mathrm{~g} \mathrm{~L}$ rhamnose (Sigma Chemical Co, Poole, Dorset, UK) in $100 \mathrm{ml}$ water. At $8 \mathrm{am}$, after an overnight fast, subjects drank the test solution. They fasted for a further 2 hours, after which they were allowed normal food and fluid intake. Complete urine collections were made for 5 hours $(8 \mathrm{am}-$ $1 \mathrm{pm}$ ) into a bottle containing $1 \mathrm{ml}$ thiomersal $(10 \% \mathrm{w} / \mathrm{v})$ as a preservative for L-rhamnose. On completion, urine values were measured and $5 \mathrm{ml}$ samples counted in an LKB Wallac $1280 \gamma$ counter along with a 1:500 dilution of the test solution. Each sample was counted for 5 minutes at appropriate channel settings giving a minimum detectable ${ }^{51} \mathrm{Cr}$ activity of less than $0.01 \%$ of the administered dose per litre of urine. Counting was done 2 weeks after completion of studies to avoid interference from urine ${ }^{111} \mathrm{In}$. The activity of ${ }^{51} \mathrm{Cr}$ from red cells in urine is trivial in comparison with the ${ }^{51} \mathrm{CrEDTA}$. The normal upper limit of the ${ }^{51} \mathrm{CrEDTA} / \mathrm{L}-$ rhamnose urine excretion ratio (\% dose) is 0.09 $(\mathrm{N}: 20)$. The estimated radiation dose received during the test is $0.24 \mathrm{mSv}$. 
Thin layer chromatography was used for estimating L-rhamnose. ${ }^{27}$ This involved measurement of peak heights by scanning densitometry incorporating an arabinose internal standard to overcome errors of application. Sugar separation was achieved by multiple development on half plates $(10 \mathrm{~cm} \times 20 \mathrm{~cm})$ of plastic backed silica gel 60 (Merk, 5748, Dassel, Germany) using three consecutive ascending runs $(8.5 \mathrm{~cm}$ each) with ethyl acetate/pyridine/ acetic acid/water (75:15:10:10, by volume). The layers were dried for at least 30 minutes between each run, and then for 4 hours (preferably overnight) to remove pyridine before performing a 4-aminobenzoic/phosphoric acid colour reaction at $120-130^{\circ} \mathrm{C}$ for 10 minutes. After location, chromatograms were kept refrigerated in polythene envelopes, and exposure was minimised during scanning. Peak heights were measured and corrected to a constant internal standard value. Test concentrations were then derived by interpolation from a standard rhamnose concentration curve from the same chromatogram.

This chromatographic procedure is accurate and sensitive, recovery being above $90 \%$ and the minimum level of detection below $0.1 \mathrm{mmol} / \mathrm{l}$ for L-rhamnose. The precision lies between 3 and $8 \%$ (coefficient of variation without replication) over the test range of sugar concentration. From the above the percentages of dose excretion of ${ }^{51} \mathrm{CrEDTA}$ and L-rhamnose in urine were calcu-

Figure 1: The 4-day faecal excretion of indium-111 before and after 2-12 weeks' treatmen vertical line indicates the upper normal limit of excretion. lated. The results are expressed as a urine excretion ratio of ${ }^{51} \mathrm{CrEDTA} / \mathrm{L}$-rhamnose which is a specific index of intestinal permeability, largely unaffected by other non-permeability variables of marker permeation rates. ${ }^{28}$

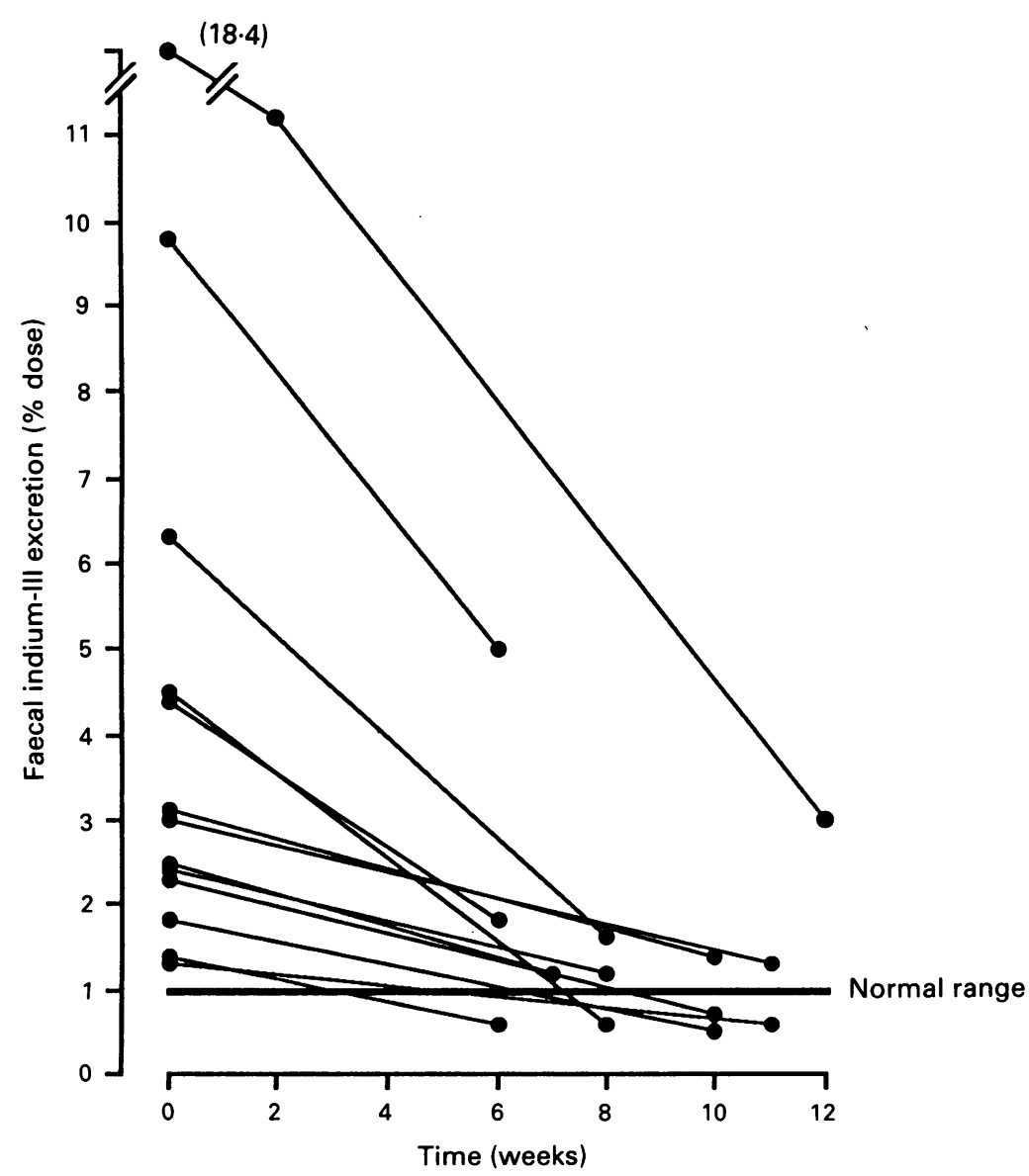

ENDOSCOPY AND HISTOLOGY

The day after the permeability test, patients on NSAIDs underwent gastroduodenoscopy (Olympus XQ20) with biopsy. Endoscopic damage was assessed by a modified Lanza score system. ${ }^{29}$ For the stomach, grades $0-3$ had $0-2$, $3-5,6-10$, and $>10$ erosions or submucosal haemorrhages respectively, and grade 4 had erosions or submucosal haemorrhages too numerous to be counted or an ulcer with clear disruption of the mucosal epithelium and a diameter greater than $0.5 \mathrm{~cm}$. In the duodenum grade $0-3$ had $0-1,2-5,6-10,>10$ erosions, and grade 4 a duodenal ulcer.

Endoscopic biopsies (N:2) were taken from each of the following sites; the mid-greater curve of the body, the greater curve in the antrum at least $2 \mathrm{~cm}$ from the pylorus and from the duodenal bulb. They were routinely formalin fixed and paraffin processed. Sections $(3 \mu \mathrm{m})$ were cut and stained with haematoxylin and eosin, periodic - acid Schiff reagent/Alcian blue and Cresyl-fast violet, the latter to aid detection of Helicobacter pylori like organisms.

Gastritis was assessed according to the Sydney system. ${ }^{30}$ In relation to this study, the key features are the grading (mild, moderate, or severe) of inflammation (lymphocytes and plasma cells), activity (neutrophil polymorphs), atrophy, intestinal metaplasia, and numbers of $H$ pylori like organisms.

\section{STATISTICAL ANALYSIS}

The paired Student's $t$ test was used to assess sequential changes.

\section{Results}

Metronidazole did not cause any adverse reaction during these studies. There was no significant change $(p>0 \cdot 1)$ in clinical disease activity, the haemoglobin concentration $(11.5$ $(1.8) v 11.6(1.8) \mathrm{g} / \mathrm{dl}$ (mean (SD)), or the erythrocyte sedimentation rate $(33$ (30) $v 30$ (29) mm hour).

\section{${ }^{111}$ In LEUKOCYTES}

The scintigrams confirmed NSAID enteropathy, and although subjective improvement was evident after treatment this cannot be quantitated accurately and hence the need for faecal analysis.

Figure 1 shows that treatment with metronidazole caused a significant reduction $(\mathrm{p}<0.001)$ in the 4 day faecal excretion of ${ }^{111}$ In leukocytes from $4 \cdot 7(4 \cdot 7) \%$ to $1 \cdot 5(1 \cdot 3) \%$. Each patient responded and after treatment five of the 13 were

TABLE II Endoscopic findings in the stomach and duodenum before and after treatment with metronidazole

\begin{tabular}{llllll}
\hline \multirow{2}{*}{$\begin{array}{llllll}\text { Endoscopic } \\
\text { grade }\end{array}$} & \multicolumn{2}{l}{ Stomach } & & & \multicolumn{2}{l}{ Duodenum } \\
\cline { 2 - 3 } & Before & After & & Before & After \\
\hline 0 & 4 & 5 & & 9 & 9 \\
1 & 2 & 2 & & 1 & 0 \\
2 & 2 & 1 & & 0 & 1 \\
3 & 2 & 1 & & 0 & 0 \\
4 & 0 & 1 & & 0 & 0 \\
\hline
\end{tabular}


within the normal range $(\mathrm{N}<1 \%, 0 \cdot 51(0 \cdot 16) \%$ (mean (SD)).

\section{RED BLOOD CELL LOSS}

Ten of 13 patients underwent ${ }^{51} \mathrm{Cr}$ red blood cell loss studies. Treatment with metronidazole caused a significant reduction in the mean daily blood loss from $2.6(1.6) \mathrm{ml} /$ day to $0.9(0.5) \mathrm{ml} /$ day $(\mathrm{p}<0.01),(\mathrm{N}<1 \mathrm{ml} / \mathrm{day}$, mean (SD) 0.2 $(0 \cdot 1) \mathrm{ml} /$ day $)$.

\section{INTESTINAL PERMEABILITY}

Figure 2 shows that there were no significant changes in the ${ }^{51} \mathrm{CrEDTA} / \mathrm{L}-$ rhamnose urine excretion ratios during metronidazole treatment. Ratios before and after treatment were 0.133 $(0.046)$ and $0.154(0.064)$ respectively $(\mathrm{p}>0 \cdot 1)$, $(\mathrm{N}<0 \cdot 09)$.

\section{ENDOSCOPY AND HISTOLOGY}

Ten patients underwent endoscopy with biopsy. Table II shows that endoscopic appearances did not change significantly during treatment. Of the 10 pairs of biopsy specimens taken from the body, antrum, and duodenum, the main abnormalities were found in the antrum. The antral specimens were normal in two, and three sets showed features typical of reactive (reflux) gastritis - a pattern associated with NSAID administration $^{31}$ - before and after treatment.

In the remaining patients the severity of the chronic inflammatory infiltrate and activity was reduced by one grade between biopsies in three patients. There was an increase of one grade in two patients. $H$ pylori like organisms were detected in two patients and persisted despite metronidazole.

\section{Discussion}

This study shows that treatment with metronida-

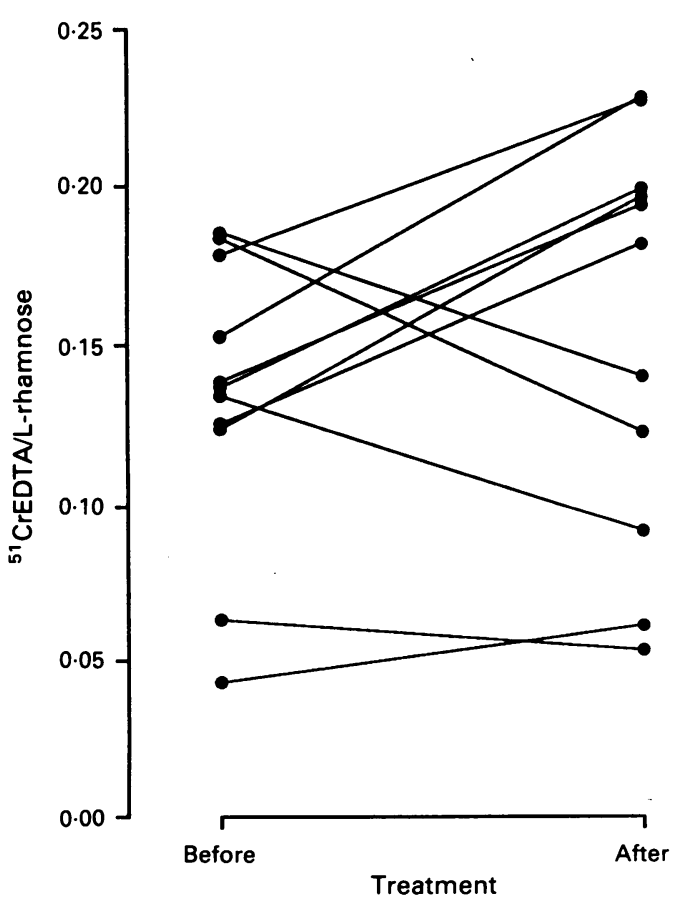

zole selectively reduces intestinal inflammation and blood loss in patients with NSAID enteropathy. The results seem to conform to the proposed pathogenic mechanism of NSAID enteropathy, namely that intestinal permeability changes predominantly reflect the direct cellular toxicity of NSAID 112 and the consequential inflammation may be a result of a bacterial invasion of the mucosa. The endoscopy results further suggest that it is the small bowel and not the stomach or duodenum that is the main site of chronic low grade blood loss in patients on long term, NSAIDs. " 12 This contrasts sharply with the life threatening bleeding in NSAID users that almost invariably originates in the stomach or duodenum. ${ }^{+6}$

Metronidazole is a narrow spectrum antibiotic with activity against primarily anaerobic organisms, particularly bacteria and protozoa. It is in the anaerobic environment alone that the drug is reduced to its active metabolite, which is thought to bind to microbial DNA and inhibit nucleic acid synthesis. The drug is used extensively in gastroenterological practice: in small bowel bacterial overgrowth and blind loop syndromes, ${ }^{32}$ in colonic Crohn's disease, and as part of combination antibiotic cover during large bowel surgery. ${ }^{33}$

Metronidazole is also known to have other actions. It may suppress cellular immunity, ${ }^{34}$ it sensitises hypoxic cells to radiation damage, and it may be mutagenic; but there is no evidence that metronidazole affects neutrophil function directly.

It therefore seems that there is a metronidazole sensitive micro-organism which is the main neutrophil chemoattractant in NSAID enteropathy. The precise characterisation of this agent awaits further study but it is clear that most patients with NSAID enteropathy have normal ${ }^{14} \mathrm{C}$ glyocholate breath tests, urinary indicans, and vitamin $B_{12}$ absorption, ${ }^{912}$ all of which may be affected in non-specific intestinal bacterial overgrowth syndromes. ${ }^{33}$ Bacteriological studies in NSAID induced small intestinal damage in experimental animals have not, however, identified a single organism. Rather, the involvement of bacteria has been inferred from studies showing that pretreatment with broad spectrum antibiotics may prevent small intestinal ulceration caused by indomethacin and that germ free animals do not seem to develop the lesions. Treating the animals with antibiotics has, however, been uniformally unsuccessful in promoting healing of indomethacin induced lesions. ${ }^{2-26}$ This contrasts with the current results and suggests that the pathogenesis of NSAID induced small intestinal inflammation differs in man and rats.

The concomitant reduction in intestinal blood loss after metronidazole treatment suggests that most of the complications of the inflammation (blood and protein loss, ileal dysfunction) are a consequence of neutrophil activation..$^{35.38}$ It is thus possible that most of the tissue damage is caused by neutrophils generating free oxygen radicals and releasing lysosomal enzymes when in contact with a chemoattractant within the lamina propria. ${ }^{35}{ }^{36}$ That metronidazole has its effect at this late stage of NSAID enteropathy is 
further supported by the findings that small intestinal permeability is not significantly affected by the treatment.

Collectively these data also suggest that the main site of NSAID induced blood loss in patients on long term NSAID treatment is the small intestine. Previous studies in man have shown a significant correlation between inflammatory activity (faecal excretion of ${ }^{111}$ In leukocytes) and ${ }^{51} \mathrm{Cr}$ red cell loss. ${ }^{12}$ This is, however, the first study that also assesses gastroduodenal damage. The changes occurring in this limited biopsy series, in particular the inflammatory infiltrate, were on a minor scale and of no consistent pattern. They are unlikely to be the origin of the abnormalities shown by the labelling techniques. As the histological damage did not change in harmony with the inflammation and blood loss, it suggests that most of the chronic intestinal blood loss is from the small intestine. This is in keeping with large endoscopy studies showing that only rarely is there a gastroduodenal cause for positive faecal blood in patients on NSAIDs. ${ }^{39}$ to Furthermore, small bowel enteroscopy in patients taking NSAIDs has confirmed the abnormalities in the mid small bowel, which range from erythematous blebs and villus atrophy to frank ulceration, all of which may bleed. ${ }^{+1}$ Combined with reduced food intake and a high gastric $\mathrm{pH}$, mild blood loss (1-8 $\mathrm{ml} /$ day) may be an important factor in the development of iron deficiency in patients with rheumatoid arthritis. ${ }^{12}$

NSAID enteropathy and its complications contribute significantly to the overall morbidity of patients receiving these drugs. Metronidazole reduces intestinal inflammation and blood loss in NSAID enteropathy but the precise mechanism has not been established. Short courses of metronidazole may be indicated in patients with problematic iron deficiency anaemia or hypoalbuminaemia but long term treatment is clearly hampered by the possibility of peripheral neuropathy and other serious side effects of metronidazole.

1 Walt R, Katschinski B, Logan R, Ashley J, Langmen M. Rising frequency of ulcer perforation in elderly people in the United Kingdom. Lancet 1986; i: 489-92.

2 CSM update. Non-steroidal anti-inflammatory drugs and serious gastrointestinal adverse reactions - 1. BMF 1986;

3 Collier DStJ, Pain JA. Non-steroidal anti-inflammatory drugs and peptic ulcer perforation. Gut 1985; 26: 359-63.

4 Matthewson K, Pugh S, Northfield TC. Which peptic ulcer patients bleed? Gut 1988; 29: 70-4.

5 O'Brien JD, Burnham WR. Bleeding from peptic ulcers and use of non-steroidal anti-inflammatory drugs in the Romford area. $B M \mathcal{F}$ 1985; 291: 1609-10.

6 Peoples JB. Peptic ulcer disease and the nonsteroidal antiinflammatory drugs. Am Surg 1985; 51: 358-62.

7 Armstrong CP, Blower AL. Non-steroidal anti-inflammatory drugs and life threatening complications of peptic ulceration. Gut 1987; 28: 527-32.

8 Bjarnason I, Williams P, So A, Zanelli G, Levi AJ, Gumpel $\mathrm{MJ}$, et al. Intestinal permeability and inflammation in $\mathrm{MJ}$, et al. Intestinal permeability and inflammation in
rheumatoid arthritis; effects of non-steroidal anti-inflammarheumatoid arthritis; effects of non-ste
tory drugs. Lancet 1984; ii: $1171-4$.

9 Bjarnason I, Zanelli G, Smith T, Prouse P, Williams P, Delacey G, et al. Nonsteroidal antiinflammatory drug induced intestinal inflammation in humans. Gastroenterology 1987; 93: 480-9.

10 Quinn CM, Price AB, Bjarnason I. Endoscopic and microscopic findings in symptomatic and asymptomatic patients on long term nonsteroidal antiinflammatory drug treatment. Gastroenterology 1990; 98: A109.

11 Bjarnason I, Zanelli G, Prouse P, Smethurst P, Smith T, Levi $S$, et al. Blood and protein loss via small intestinal inflammation induced by non-steroidal anti-inflammatory drugs. Lancet 1987; ii: $711-4$.
12 Bjarnason I. Non-steroidal anti-inflammatory drug induced small intestinal inflammation in man. In: Pounder RE, ed. Recent advances in Gastroenterology - 7. London: Churchill Livingstone, 1988: 23-46.

13 Biarnason I, Zanelli G, Smethurst P, Burke M, Gumpel MJ, Price AB, et al. Clinicopathological features of NSAID induced small intestinal strictures. Gastroenterology 1988; 94: $1070-4$.

14 Lang J, Price AB, Levi AJ, Burke M, Gumpel MJ, Bjarnason I. Diaphragm disease: the pathology of non-steroidal antiinflammatory drug induced disease of the small intestine. F Clin Pathol 1988; 41: 516-26.

15 Hansen TM, Hansen NE, Birgens HS, Hölund B, Lorenzen I. Serum ferritin and the assessment of iron deficiency in rheumatoid arthritis. Scand $\mathcal{F}$ R heumatol 1983; 12: 353-9.

16 Vreugdenhil G, Wognum AW, Vaneijk HG, Swaak AJG. Anaemia in rheumatoid arthritis: the role of iron, vitamin $\mathrm{B}_{12}$, and folic acid deficiency, and erythropoietin responsiveness. Ann Rheum Dis 1990; 49: 93-8.

17 Bjarnason Z, Zanelli G, Smith I, Smethurst P, Price AB, Gumpel MJ, et al. The pathogenesis and consequence
of non-steroidal anti-inflammatory drug induced small of non-steroidal anti-inflammatory drug induced small (suppl 69): 55-67

18 Bjarnason I, Macpherson A. The changing side effect profile of non-steroidal antiinflammatory drugs. A new approach for the prevention of a new problem. Scand $\mathcal{F}$ Gastroenterol 1989; 24 (suppl 163): 56-64

19 Bjarnason I, Williams P, Smethurst P, Peters TJ, Levi AJ. The effects of non-steroidal anti-inflammatory drugs and prostaglandins on the permeability of the human small bowel. Gut 1986; 27: 1292-7.

20 Jenkins RT, Rooney PJ, Jones DB, Bienenstock J, Goodacre RC. Increased intestinal permeability in patients with rheumatoid arthritis: A side effect of oral nonsteroidal rheumatoid arthritis: A side effect of oral nonsteroidal
antiinflammatory drug therapy. $B r \mathcal{F}$ Rheumatol 1987; 26: antiinfl.

21 Bjarnason I, Smethurst P, Fenn CG, Lee CF, Menzies IS, Levi AJ. Misoprostol reduces indomethacin induced changes in human small intestinal permeability. Dig Dis Sci 1989; 34: 407-11.

22 Kent TH, Cardeli RM, Stanler FU. Small intestinal ulcers and intestinal flora in rats given indomethacin. Am $\mathcal{F}$ Pathol 1969; 54: 237-45.

23 Benoni G, Del Soldato P, Cuzzolin L, Velo GP. Role of intestinal microflora in maintaining indomethacin-induced intestinal lesions in rats. In: Rainsford K, Velo GP, eds. Side effects of anti-inflammatory drugs. Part II. Lancaster: MTP Press Limited, 1987: 83-7.

24 Satoh H, Guth PH, Grossman MI. Role of bacteria in gastric ulceration produced by indomethacin in the rat: cytoprotective action of antibiotics. Gastroenterology 1983; 84: 483-9.

25 Robert A, Asano T. Resistance of germ free rats to indomethacin-induced lesions. Prostaglandins 1977; 14: $331-41$.

26 Bjarnason I, Smethurst P, Levi AJ, Price AB. Indomethacin induced chronic small intestinal ulceration in the rat. Gastroenterology 1988; 94: 1937.

27 Menzies IS, Mount JN, Wheeler MJ. Quantitative estimation of clinically important monosaccharides in plasma by rapid thin-layer chromatography. Ann Clin Biochem 1978; 15: thin-layer.

28 Menzies IS. Transmucosal passage of inert molecules in health and disease. In: Skadhauge E, Heintze $\mathrm{K}$, eds. Intestinal absorption and secretion. FALK Symposium 36. Lancaster: MTP Press Limited, 1984: 527-43.

29 Lanza FL, Royer GL, Nelsor RS, Chen TJ, Seckman CD, Rack MF. A comparative endoscopic evaluation of the damaging effects of nonsteroidal antiinflammatory agents on the gastric and duodenal mucosa. Am $\mathcal{F}$ Gastroenterol 1981; 75: 17-21.

30 Price AB. Sydney system: histological divisions. $\mathcal{F}$ Gastroenterol Hepatol 1991; 6: 209-22.

31 Sobala GM, Keng RFG, Axon ATR, Dixon R. Reflux gastritis in the intact stomach. $\mathcal{F}$ Clin Pathol 1990; 43: 303-6.

32 Bjornerklett A, Hoversted T, Hovid T. Bacterial overgrowth Scand $\mathcal{F}$ Gastroenterol 1985; 20 (suppl 109): 123-30.

33 Tabaqchali S, Booth CC. Bacterial overgrowth. In: Booth CC, Neale G, eds. Disorders of the small intestine. Oxford: Blackwell Scientific Publications, 1985: 249-69.

34 Miller JJ. The imidazoles as immunosuppression agents. Transplant Proc 1980; 12: 300-4.

35 Malech ML, Callin JI. Neutrophils in human disease. $N E n g l$ F Med 1987; 317: 687-94.

36 Weiss SJ. Tissue destruction of neutrophils. $N$ Engl f Med 1989; 320: 365-76.

37 Wallace JL, Arfors KE, McKnight GW. A monoclonal antibody against the $\mathrm{CD} 18$ leukocyte adhesion molecule prevents indomethacin induced gastric damage in the rabbit. prevents indomethacin induced gast

38 Wallace JL, Keenan CM, Granger DN. Gastric ulceration induced by nonsteroidal anti-inflammatory drugs is a induced by nonsteroidal anti-inflammatory drugs is a
neutrophil-dependent process. Am $\mathcal{F}$ Physiol 1990; 259: G462-7.

39 Collins AJ, Du Toit JA. Upper gastrointestinal findings and faecal blood in patients with rheumatic diseases taking nonsteroidal anti-inflammatory drugs. Brf Rheumatol 1987; 26: $295-8$.

40 Bartle WR, Gupta AK, Lazon J. Nonsteroidal antiinflammatory drugs and gastro-intestinal bleeding. A case control study. Arch Intern Med 1986; 146: 2365-7.

41 Morris J, Madhok R, Sturrock RD, Capell HA, Mackenzie JF. Enteroscopic diagnosis of small bowel ulceration in patients receiving non-steroidal anti-inflammatory drugs. Lancet 1991; i: 520 . 